กORTH CLIn ISTAกBUL 2015;2(1):7-12

doi: $10.14744 /$ nci.2015.83007

\title{
Frequency of left atrial dilatation in ischemic stroke
}

\author{
Handan Cemile Misirli ${ }^{1}$, Havva Tugba Yanar ${ }^{2}$, Serife Nese Erdogan ${ }^{1}$, \\ Elvan Cevizci Akkilic ${ }^{3}$, Duygu Ozkan, Tamer Bayram¹, Ozkan Araz ${ }^{1}$ \\ 1Department of Neurology, Haydarpasa Numune Training and Research Hospital, Istanbul, Turkey \\ 2Department of Neurology, Erzurum Horasan State Hospital, Erzurum, Turkey \\ ${ }^{3}$ Department of Neurology, Bingol State Hospital, Bingol, Turkey \\ ${ }^{4}$ Department of Neurology, Duzce State Hospital, Duzce, Turkey
}

\section{ABSTRACT}

OBJECTIVE: The study aimed to evaluate the frequency of left atrial dilatation in cases of first-ever acute ischemic stroke with or without atrial fibrillation in a cohort of patients hospitalized for ischemic stroke.

METHODS: Files of 120 patients admitted to our hospital with the diagnosis of acute ischemic stroke were investigated. All patients had at least one brain imaging. Etiology of stroke was categorized according to Trial of Org 10172 in Acute Stroke Treatment (TOAST) classification. Transthoracic and/or transoesophageal echocardiography was used to measure left atrium size. Optimal cut-off value of left atrial diameter was determined as $4 \mathrm{~cm}$. SPSS 11.5 was used for statistical analyses.

RESULTS: In $40 \%$ of the patients, left atrial dilatation was detected. Nineteen patients with left atrial dilatation had atrial fibrillation, which was statistically significant $(p<0.05)$. Ninety-four $(30.8 \%)$ patients with no atrial fibrillation had left atrial dilatation. In the TOAST classification trial, as a statistically significant finding, left atrial dilatation was detected $68.9 \%$ of the patients with cardioembolic infarcts. The most frequently encountered risk factor in patients was hypertension.

CONCLUSION: Left atrial dilatation is an important marker for cerebrovascular diseases, and if accompanied by atrial fibrillation becomes even more significant.

Key words: Atrial fibrillation; echocardiography; ischemic stroke; left atrial dilatation.

Astrouge
undefined
rienced an
evaluation left atrial dilatation (LAD) has been shown to be a significant predictor of cardiovascular and cerebrovascular outcomes. It is strongly associated with an increased risk of atrial fibrillation $(\mathrm{AF})$, which is a major risk factor stroke $[3,4]$. It has been also as-

Received: December 05, 2014 Accepted: December 30, 2014 Online: April 23, 2015

Correspondence: Dr. Handan Cemile MISIRLI. Haydarpasa Numune Egitim ve Arastirma Hastanesi, Noroloji Anabilim Dali, Istanbul, Turkey.

Tel: +90 216 - 54232 32/1423 e-mail: handanmisirli@yahoo.com

(c) Copyright 2015 by Istanbul Northern Anatolian Association of Public Hospitals - Available online at www.kuzeyklinikleri.com 
sociated with hypertension (HT) and thrombus formation. In this study, we aimed to echocardiographically evaluate the frequency of LAD in patients with first-ever acute ischemic stroke with or without atrial fibrillation.

\section{MATERIALS AND METHODS}

Files of 865 patients who were admitted to the Neurology Department of our hospital with a first-ever in life acute ischemic stroke experienced between the years of 2009 and 2012 were investigated. Of those, 120 patients aged above 45 were included in the study. We excluded the patients if they had a previous ischemic or hemorrhagic stroke, vasculitis and sinus thrombosis. Ischemic stroke was defined as clinical signs of focal cerebral dysfunction of presumed ischemic origin lasting more than 24 hours [5].

Clinical information including age, sex, history of smoking, alcohol consumption, dyslipidemia, diabetes mellitus, cardiac disease, presence of hypertension, peripheral artery disease, history of stroke in the family, obstructive sleep apnea syndrome and prestroke use of antiaggregants and/or statins were noted.

Hypertension (HT) was considered to be present if at the time of the diagnosis subjects had a systolic blood pressure (BP) $140 \mathrm{Mm} \mathrm{Hg}$ or a diastolic BP $90 \mathrm{mmHg}$, and if treatment for high blood pressure was administered previously. Diabetes mellitus (DM) was considered to be present if the subjects had a serum level of glucose $>110 \mathrm{mg} / \mathrm{dl}$ or if treatment had been previously initiated for hyperglicemia. Patients with abnormal levels of total cholesterol ( $\geq 200 \mathrm{mg} / \mathrm{dl}$ ), HDL-C (men, $\leq 40 \mathrm{mg}$ / $\mathrm{dl}$; women $\leq 50 \mathrm{mg} / \mathrm{dl})$, LDL-C $(\geq 130 \mathrm{mg} / \mathrm{dl})$, and triglyceride $(>150 \mathrm{mg} / \mathrm{dl})$, and those on antihyperlipidemic treatment were accepted as having dyslipidemia (DSL). Cardiac disease was considered to be present if cardiac pathology had been observed at the time of the diagnosis or if the subjects had a history of atrial fibrillation, myocardial infarction, angina pectoris, by-pass surgery and severe (>50\%) coronary artery stenosis.

Patients were assessed by a complete physical and neurological examination, routine hematological, biochemical and microbiological analyses, chest Xrays, 12-lead electrocardiography, Doppler ultrasonography and echocardiography. In patients without any risk factors, transoesophageal echocardiography was performed after transthoracic echocardiography. All patients had at least one brain imaging. Brain computed tomography, and MRI scan scans were performed in 100 , and $46 \%$ of the patients, respectively.

Stroke subtypes were determined based on a modified Trial of Org 10172 in Acute Stroke Treatment (TOAST) classification system [6].

Standard transthoracic echocardiography was performed in all patients using Vivid Three System within $72 \mathrm{~h}$ of their admissions. Standard views in the left lateral decubitus and supine positions, were obtained [7].

Echocardiography results of the patients were analyzed to determine the presence of LAD. Left atrial diameters were assessed statistically. LADs were classified as mild (men, $4.1-4.6 \mathrm{~cm}$ or women, $3.9-4.2 \mathrm{~cm}$ ), moderate (men, 4.7-5.1 cm or women, $4.3-4.6 \mathrm{~cm}$ ) or severe dilated (men, $>5.2 \mathrm{~cm}$ or women, $4.7 \mathrm{~cm}$ ) in accordance with the recommendations of the American Society of Echocardiography $[7,8]$.

The cut-off threshold value was found to be 4 $\mathrm{cm}$, and diameters above that threshold were considered to represent LAD. The study protocol was presented to the regional ethics committee and the board gave approval for the study.

SPSS 11.5 was used for statistical analyses. Continuous variables were represented as mean \pm standard deviation and median, while categorical variables were represented as numbers and percentages. Mann-Whitney U Test, and Kruskal-Wallis Test were used to compare continuous, and categorical variables, respectively.

Chi-square test was used to define the differences between groups. Level of statistical significance was set at $\mathrm{p}<0.05$.

\section{RESULTS}

In this study, 120 patients (65 male, 55 female) eval- 
uated in our department without any statistical significance between genders $(p>0.05)$. The mean age was 68.7 years (standard deviation 10.9). The most common risk factor was HT $(71.7 \%)$, followed by diabetes mellitus (DM) (66.6\%). The other risk factors are shown in Table 1.

Patients were distributed into two groups as those with or without LAD. Of 120 patients, 48 (40\%) had LAD.

Patients with LAD composed of 26 men (54.2\%) and 22 women (45.2\%) with no statistical significance between them. Mean ages of male, and female patients were 67.8 , and 75.6 years, respectively with a statistically significant difference between genders $(p<0.05)$.

Nineteen patients with LAD had AF which was statistically significant $(p<0.05)$ (Figure 1$)$. On the other hand, 94 (30.8\%) patients without AF had LAD (Table 2).

According to the investigation done based on TOAST classification, large-artery atherosclerosis (LAAS) $(n=20)$, cardioembolic infarcts (CE) $(n=45)$, lacunary infarcts $(L A C)(n=28)$ and LAD of undetermined origin $(n=27)$ were identified. LAD was found in patients with LAAS (20\%), CE (68.9\%), LAC (28.5\%), and diseases yet undetermined origin (18.5\%) (Figure 2). According to TOAST classification the frequency of LAD in the CE group was significantly higher $(p<0.01)$ compared to the other groups.

\section{DISCUSSION}

Cerebrovascular diseases are the second leading cause of death in our country, accounting for $15 \%$ of all deaths. Loss of ability is the third one with a rate of $5.9 \%$ [9].

Predicting outcome and mortality is important in acute ischemic stroke for optimizing care and treatment decision. The etiology of ischemic stroke effects its prognosis, outcome and management [9, $10]$. Despite significant achievement in the diagnosis and treatment of stroke, it is still difficult to diagnose ischemic stroke subtypes at admission and predict mortality $[11,12]$.
TABLE 1. Distribution of risk factors

\begin{tabular}{llll} 
Risk factors & Left atrial dilatation & $\mathrm{n}$ & $\%$ \\
\hline Hypertension & & & \\
& Yes & 86 & 71.7 \\
& No & 34 & 28.3
\end{tabular}

$\mathrm{DM}^{*}$

$\begin{array}{lll}\text { Yes } & 40 \quad 33.3\end{array}$

No $\quad 80 \quad 66.6$

$\mathrm{AF}^{*}$

$\begin{array}{llll}\text { Yes } & 26 & 21.0\end{array}$

Smoking§

$\begin{array}{lll}\text { No } & 94 & 78.3\end{array}$

$\begin{array}{llll}\text { Yes } & 42 & 35.0\end{array}$

Dyslipidemia

$\begin{array}{lll} & \text { No } & 78\end{array}$

\begin{tabular}{lccc} 
& Yes & 29 & 24.0 \\
Thrombosis & No & 91 & 75.8 \\
& & & \\
& Yes & 2 & 1.6 \\
Sec $^{\square}$ & No & 118 & 98.3 \\
& & & \\
Heart disease & Yes & 5 & 4.1 \\
& No & 115 & 95.8 \\
& & & \\
& Yes & 24 & 19.9 \\
& No & 216 & 81.1 \\
\hline
\end{tabular}

*Diabetes mellitus; ${ }^{\star}$ Atrial fibrillation; ${ }^{\S}$ Smoking; $\square$ Spontaneous echo contrast.

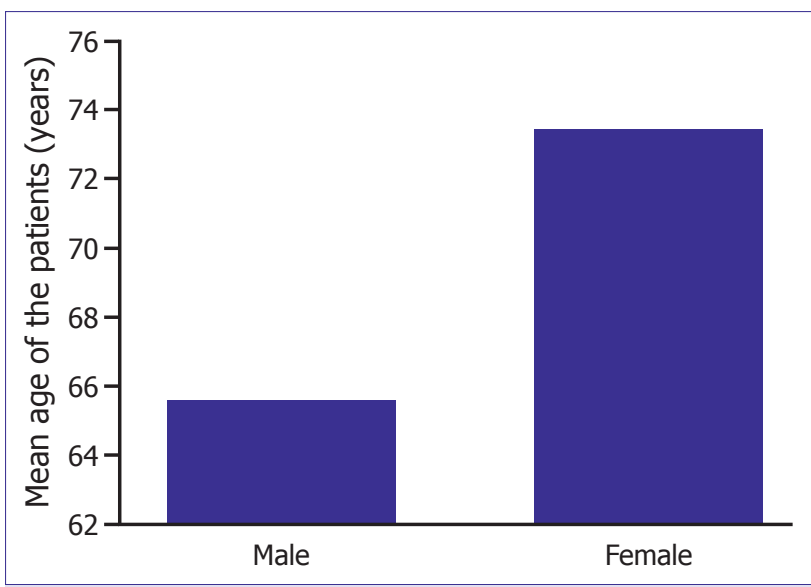

FIGURE 1. Mean age of male and female patients with atrial dilatation. 
Twenty percent of ischemic strokes have cardiological origin and their clinical status is more severe and has a higher risk of recurrence in the short term follow-up compared to the other stroke groups [12, 13]. Even in $50 \%$ of those people who die from a heart disease, cerebral infarction has been found in the autopsy findings. Based on this strong evidence, echocardiography is a preferred method for evaluating patients who may have had a cardioembolic stroke $[14,15]$. In our study, cardioembolic group had the highest number of patients and LAD had the significantly higher incidence $(68.9 \%)$ in the cardioembolic group.

Besides many other cardiovascular risk factors, left atrial dilatation also increased stroke and $\mathrm{AF}$ risks as reported in some recent studies $[16,17]$. The etiology of stroke risk is not so clear, but there are some potential mechanisms that have been proposed. One of them is that LAD is a strong risk factor for $\mathrm{AF}$ or paroxysmal $\mathrm{AF}$ and this relationship increases the occurrence of stroke. Another probable explanation is that in the existence of LAD, left atrial mean velocity is decreased and spontaneous echo contrast (SEC) or development of thrombosis may be seen in the left atrium $[18,19,20]$. In this study, we found four SEC and two thrombi in the echocardiograms of our patients with no statistical significance. Another study showed that the association of LAD with premature ventricular heart beats increased the stroke risk [21].

Atrial fibrilation is a frequently encountered arrhytmia associated with increased morbidity and mortality. Several large population-based studies have shown a strong association between LAD and the risk of new-onset $\operatorname{AF}[4,22,23]$. In the Framingham Heart Study, every $5 \mathrm{~mm}$ increase in the left atrial diameter increased the development of AF by 39\%. Cardiovascular Health Study showed a fourfold increase in the risk of AF with left atrial diameter of $>0.5 \mathrm{~mm}$. In our study, 19 (39.5\%) patients with LAE had AF and the result was statistically significant $(p<0.05)$.

In many studies, it was considered that there could be a relationship between left atrial dilatation and HT. It is not so clear if this relates to left ventricular hyperthrophy or there is a direct rela-
TABLE2. Relationship of left atrial dilatation and AF

Left atrial dilatation

\begin{tabular}{|c|c|c|c|c|}
\hline & & & Yes & No \\
\hline \multicolumn{5}{|c|}{$\mathrm{AF}^{*}$} \\
\hline & \multirow[t]{2}{*}{ Yes } & $\mathrm{n}$ & 19 & 7 \\
\hline & & $\%$ & 39.58 & 9.72 \\
\hline & \multirow[t]{2}{*}{ No } & $\mathrm{n}$ & 29 & 65 \\
\hline & & $\%$ & 60.42 & 90.28 \\
\hline & \multirow[t]{2}{*}{ Total } & $\mathrm{n}$ & 48 & 72 \\
\hline & & $\%$ & 100 & 100 \\
\hline
\end{tabular}

*Atrial fibrillation.

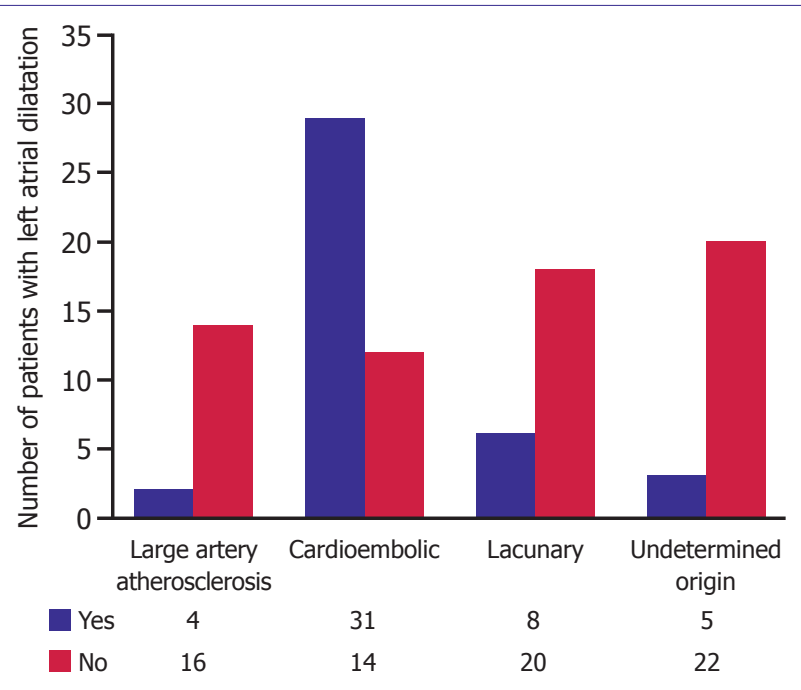

FIGURE2. Distribution of left atrial dilatation according to TOAST classification.

tionship between HT, and left atrila dilatation [24]. Left atrial dilatation, left atrial volume indexes and the distance between left atrium and aortic root were found to be significantly higher in the hypertensive patients than the normotensive people $[16$, $23,25]$. With its thin wall, left atrium dilates easily. As a result of this, LAD in echocardiography may be evaluated as an early finding of hypertensive heart disease $[3,7,26]$. Although the Framingham Study risk profile is useful and includes well-recognized stroke risk factors- like age, HT, DM, smok- 
ing- many people have suffered from strokes despite low risk profile score. In our study, 38 out of 86 patients with HT had LAD and this result was not statistically significant $(p=0,01)$. Other known risk factors also didn't have any significance. In another study, it was shown that HT with diastolic dysfunction causes chronic left ventricular filling pressure and left atrial remodeling $[18,27]$.

Bouzas-Mosquera and colleagues described an independent association between left atrial size on echocardiography and stroke risk solely in women [28]. However prior studies reported a similar relationship between left atrial size and ischemic stroke risk only in men $[3,29,30]$. In our study, there was no relationship between the gender and the stroke risk with $\mathrm{LAD}$. On the other hand, mean age of the women who had stroke risk was higher than men, carrying a risk for stroke without any statistical significant difference between genders. Ninety-four patients with LAD didn't have AF which indicates that apparent relationship between left atrial size and stroke does not invariably involve AF [31]. In our study, we detected significant involvement of AF in cardioembolic strokes. In our country Takoğlu, et al. observed also the same result in the undetermined LAD group $(p<0.038)[32]$.

Some studies using left atrial volume-instead of left atrial dilatation-have predicted AF in elderly patients [22,33]. Recently, in elderly patients without AF at baseline, left atrial volume indexes $>32 \mathrm{~mL} /$ $\mathrm{m}^{2}$ were independently predictive of a first ischemic stroke. A recent prospective study has found that not only the maximum but also the minimum left atrial volume were independent predictors of first AF [33]. We couldn't measure the left atrial volume in our study.

Our study has some limitations. Firstly, the number of stroke patients included in the study was relatively small, and the patients were randomly selected. Secondly, we couldn't investigate paroxysmal AF with at least 24-hour ECG monitoring, so AF frequency may be lower than expected in our study. Thirdly, we didn't evaluate left atrial volume indexes relative to body surface area or body height, since recent literatures concerning left atrial size have emphasized the importance of the left atrial volume rather than the left atrial dilatation. In conclusion, LAD is poorly linked with risk factors of stroke. Atrial fibrillation is seen at a large extent in cardioembolic strokes and LAD is associated significantly with $\mathrm{AF}$, but $\mathrm{AF}$ is not a prerequisite for stroke development. We haven't found any relationship between gender of the patients and the stroke risk. It would be ideal to perform these studies with larger number of ischemic stroke patients in the future with special emphasize on atrial volume.

Conflict of Interest: No conflict of interest was declared by the authors.

Financial Disclosure: The authors declared that this study has received no financial support.

\section{REFERENCES}

1. Amarenco P, Bogousslavsky J, Caplan LR, Donnan GA, Hennerici MG. Classification of stroke subtypes. Cerebrovasc Dis 2009;27:493-501. CrossRef

2. D'Agostino RB, Wolf PA, Belanger AJ, Kannel WB. Stroke risk profile: adjustment for antihypertensive medication. The Framingham Study. Stroke 1994;25:40-3. CrossRef

3. Benjamin EJ, D’Agostino RB, Belanger AJ, Wolf PA, Levy D. Left atrial size and the risk of stroke and death. The Framingham Heart Study. Circulation 1995;92:835-41. CrossRef

4. Sanfilippo AJ, Abascal VM, Sheehan M, Oertel LB, Harrigan P, Hughes RA, et al. Atrial enlargement as a consequence of atrial fibrillation. A prospective echocardiographic study. Circulation 1990;82:792-7. CrossRef

5. Goldstein LB, Bushnell CD, Adams RJ, Appel LJ, Braun LT, Chaturvedi $\mathrm{S}$, et al. Guidelines for the primary prevention of stroke: a guideline for healthcare professionals from the American Heart Association/American Stroke Association. Stroke 2011;42:517-84. CrossRef

6. Adams HP Jr, Bendixen BH, Kappelle LJ, Biller J, Love BB, Gordon DL, et al. Classification of subtype of acute ischemic stroke. Definitions for use in a multicenter clinical trial. TOAST. Trial of Org 10172 in Acute Stroke Treatment. Stroke 1993;24:35-41.

7. Lang RM, Bierig M, Devereux RB, Flachskampf FA, Foster E, Pellikka PA, et al. Recommendations for chamber quantification: a report from the American Society of Echocardiography's Guidelines and Standards Committee and the Chamber Quantification Writing Group, developed in conjunction with the European Association of Echocardiography, a branch of the European Society of Cardiology. J Am Soc Echocardiogr 2005;18:1440-63.

8. Lerakis S, Nicholson WJ. Part Iः use of echocardiography in the evaluation of patients with suspected cardioembolic stroke. Am J Med Sci 2005;329:310-6. CrossRef

9. Ozturk S. Epidemiology of cerebrovascular diseases and risk 
factors-perspectives of the world and Turkey. Turk J Geriatr 2009;13:51-8.

10. Ferro JM. Cardioembolic stroke: an update. Lancet Neurol 2003;2:177-88. CrossRef

11. Biteker M, Ozden T, Dayan A, Tekkeşin AI, Mısırlı CH. Aortic stiffness and plasma brain natriuretic peptide predicts mortality in acute ischemic stroke. Int J Stroke 2013. CrossRef

12 Murtagh B, Smalling RW. Cardioembolic stroke. Curr Atheroscler Rep 2006;8:310-6. CrossRef

13. Lee LJ, Kidwell CS, Alger J, Starkman S, Saver JL. Impact on stroke subtype diagnosis of early diffusion-weighted magnetic resonance imaging and magnetic resonance angiography. Stroke 2000;31:1081-9. CrossRef

14. Michel P, Odier C, Rutgers M, Reichhart M, Maeder P, Meuli R, et al. The Acute STroke Registry and Analysis of Lausanne (ASTRAL): design and baseline analysis of an ischemic stroke registry including acute multimodal imaging. Stroke 2010;41:2491-8.

15. Rauh R, Fischereder M, Spengel FA. Transesophageal echocardiography in patients with focal cerebral ischemia of unknown cause. Stroke 1996;27:691-4. CrossRef

16. Kim BS, Lee HJ, Kim JH, Jang HS, Bae BS, Kang HJ, et al. Relationship between left atrial size and stroke in patients with sinus rhythm and preserved systolic function. Korean J Intern Med 2009;24:24-32. CrossRef

17. Nagarajarao HS, Penman AD, Taylor HA, Mosley TH, Butler $\mathrm{K}$, Skelton TN, et al. The predictive value of left atrial size for incident ischemic stroke and all-cause mortality in African Americans: the Atherosclerosis Risk in Communities (ARIC) Study. Stroke 2008;39:2701-6. CrossRef

18. Giménez DM, Torres F, Franco M, Vivancos R, Anguita M, Granados AL, et al. An analysis of the factors and phenomena associated with the formation of a spontaneous echo contrast in the left atrium. [Article in Spanish] Rev Esp Cardiol 1994;47:181-6. [Abstract]

19. Rossi A, Cicoira M, Zanolla L, Sandrini R, Golia G, Zardini $\mathrm{P}$, et al. Determinants and prognostic value of left atrial volume in patients with dilated cardiomyopathy. J Am Coll Cardiol 2002;40:1425. CrossRef

20. Chimowitz MI, DeGeorgia MA, Poole RM, Hepner A, Armstrong WM. Left atrial spontaneous echo contrast is highly associated with previous stroke in patients with atrial fibrillation or mitral stenosis. Stroke 1993;24:1015-9. CrossRef

21. Cozma DC, Mornos C, Ionac A, Petrescu L, Tutuianu C, Dragulescu SI. Institute of Cardiovascular Medicine-Timisoara-
Romania. Left atrial dilatation and shape remodeling in frequent premature ventricular contraction: a possible explanation for stroke risk. Eur J Echocardiography Abstracts Supplement 2011;12:2.

22. Barnes ME, Miyasaka Y, Seward JB, Gersh BJ, Rosales AG, Bailey $\mathrm{KR}$, et al. Left atrial volume in the prediction of first ischemic stroke in an elderly cohort without atrial fibrillation. Mayo Clin Proc 2004;79:1008-14. CrossRef

23. Tsang TS, Barnes ME, Bailey KR, Leibson CL, Montgomery $\mathrm{SC}$, Takemoto $\mathrm{Y}$, et al. Left atrial volume: important risk marker of incident atrial fibrillation in 1655 older men and women. Mayo Clin Proc 2001;76:467-75. CrossRef

24. Gerdts E, Wachtell K, Omvik P, Otterstad JE, Oikarinen L, Boman $\mathrm{K}$, et al. Left atrial size and risk of major cardiovascular events during antihypertensive treatment: losartan intervention for endpoint reduction in hypertension trial. Hypertension 2007;49:311-6. CrossRef

25. Patel DA, Lavie CJ, Milani RV, Shah S, Gilliland Y. Clinical implications of left atrial enlargement: a review. Ochsner J 2009;9:191-6.

26. Pritchett AM, Mahoney DW, Jacobsen SJ, Rodeheffer RJ, Karon BL, Redfield MM. Diastolic dysfunction and left atrial volume: a population-based study. J Am Coll Cardiol 2005;45:87-92. CrossRef

27. Vaziri SM, Larson MG, Benjamin EJ, Levy D. Echocardiographic predictors of nonrheumatic atrial fibrillation. The Framingham Heart Study. Circulation 1994;89:724-30. CrossRef

28. Bouzas-Mosquera A, Broullón FJ, Álvarez-García N, Méndez E, Peteiro J, Gándara-Sambade T, et al. Left atrial size and risk for all-cause mortality and ischemic stroke. CMAJ 2011;183:65764. CrossRef

29. Di Tullio MR, Sacco RL, Sciacca RR, Homma S. Left atrial size and the risk of ischemic stroke in an ethnically mixed population. Stroke 1999;30:2019-24. CrossRef

30. Goldstein LB. Left atrial enlargement: a cause of stroke? CMAJ 2011;183:1129-30. CrossRef

31. Khidhir AJ, Al-Shimmery EK, Alwan MH. Are left atrial abnormalities a risk for stroke? Neurosciences (Riyadh) 2010;15:21-6.

32. Takoğlu A, Can U. Left atrial dilatation in undetermined group according to TOAST classification: echocardiographic assessment of stroke patients. Turk J Med Sci 2013;43:957-62. CrossRef

33. Fatema K, Barnes ME, Bailey KR, Abhayaratna WP, Cha S, Seward JB, et al. Minimum vs. maximum left atrial volume for prediction of first atrial fibrillation or flutter in an elderly cohort: a prospective study. Eur J Echocardiogr 2009;10:282-6. CrossRef 